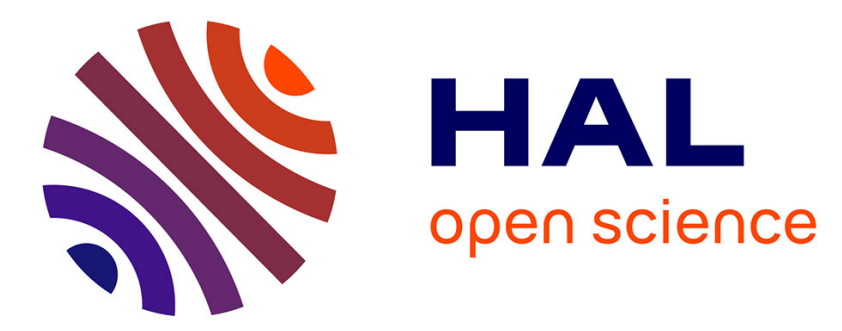

\title{
One-pot synthesis of organic polymer functionalized mesoporous silicas
}

Thuy T.T. Ngo, Eric Besson, Emily Bloch, Sandrine Bourrelly, Richard Llewellyn, S. Gastaldi, Philip Llewellyn, Didier Gigmes, Trang N.T. Phan

\section{To cite this version:}

Thuy T.T. Ngo, Eric Besson, Emily Bloch, Sandrine Bourrelly, Richard Llewellyn, et al.. One-pot synthesis of organic polymer functionalized mesoporous silicas. Microporous and Mesoporous Materials, 2021, 319, pp.111036. 10.1016/j.micromeso.2021.111036 . hal-03327297

\section{HAL Id: hal-03327297 \\ https://hal.science/hal-03327297}

Submitted on 16 Nov 2021

HAL is a multi-disciplinary open access archive for the deposit and dissemination of scientific research documents, whether they are published or not. The documents may come from teaching and research institutions in France or abroad, or from public or private research centers.
L'archive ouverte pluridisciplinaire $\mathbf{H A L}$, est destinée au dépôt et à la diffusion de documents scientifiques de niveau recherche, publiés ou non, émanant des établissements d'enseignement et de recherche français ou étrangers, des laboratoires publics ou privés.

\section{(ㅇ)(1) $\$$}

Distributed under a Creative Commons Attribution - NonCommercial - NoDerivatives $\mid 4.0$ 


\section{One-Pot Synthesis of Organic Polymer Functionalized Mesoporous Silicas}

Thuy T. T. Ngo, ${ }^{a}$ Eric Besson, ${ }^{a^{*}}$ Emily Bloch, ${ }^{\mathrm{b}}$ Sandrine Bourrelly, ${ }^{\mathrm{b}}$ Richard Llewellyn, ${ }^{\mathrm{a}}$ Stéphane Gastaldi, ${ }^{a}$ Philip L. Llewellyn, ${ }^{b, c}$ Didier Gigmes, ${ }^{a}$ Trang N. T. Phan ${ }^{a}$ *

${ }^{a}$ Aix Marseille Univ, CNRS, ICR, Marseille, France

${ }^{b}$ Aix Marseille Univ, CNRS, MADIREL, Marseille, France

${ }^{c}$ TOTAL SE, Centre Scientifique et Technique Jean Féger, Pau, France

Corresponding Author.

Trang N.T.Phan:trang.phan@univ-amu.fr,Eric Besson:eric.besson@univ-amu.fr

ABSTRACT: Polymer functionalization of ordered mesoporous silicas (OMS) offer wide applications owing to their synergy properties. In this study, a new approach for polymer functionalization of OMS is demonstrated by the co-condensation of silica precursor and a functional polymer bearing triethoxysilane end-group in the presence of a tailored poly(ethylene oxide)-b-polystyrene (PEO-b-PS) amphiphilic copolymer used as pore template. The novelty of this strategy resides in the co-micellization of PEO- $b$-PS and functional polymer that enables the incorporation of the latter into the mesoporous silica. By changing the nature of the functional polymer, as well as their loading concentration and process conditions, different ordered polymermesoporous silicas containing aryl, nitro or amide groups and high polymer content, up to $38 \mathrm{wt} \%$ were synthesized. These materials exhibit high specific surface area $\left(488 \mathrm{~m}^{2} \mathrm{~g}^{-1}\right)$ and large pores $(8 \mathrm{~nm})$ with acceptable $\mathrm{CO}_{2}$ adsorption capacity and selectivity towards $\mathrm{CH}_{4}$ and $\mathrm{N}_{2}$.

KEYWORDS: mesoporous silica, hybrid materials, gas adsorption.

\section{Introduction}

Organic-inorganic hybrid mesoporous silicas are a class of materials in which the inorganic support provides mechanical and thermal stability while the organic layer adds specific chemical 
functionalities [1]. These materials provide a synergy between the organic and inorganic phase properties, are characterized by large specific surface areas and tunable pore sizes, i.e. between 2 and $15 \mathrm{~nm}$. They have found various applications in fields such as catalysis [2], gas adsorption [3], biomedicine $[4,5]$, etc... The possibility to perfectly control their chemical and topological features explains the success of these materials. Indeed, the versatility of the sol-gel process enables the preparation of an ordered porous framework with a fine control of the organic function localization thanks to a smart choice of the synthesis conditions and the organic building-blocks.

Ordered porous frameworks can mainly be built by two pathways, that are liquid-crystal templating processes (Evaporation-induced self-assembly (EISA)) and cooperative self-assembly [6]. Both methods have benefits and drawbacks and the choice of the synthetic pathway depends on the structure and the shape of the desired final material [7]. The first method, relatively flexible, involves the use of a liquid crystalline mesophase obtained by a high concentration of surfactant. But the release of alcohols upon hydrolysis of alkoxide precursors can interfere with the initial lyotropic liquid crystal phase. In order to overcome this drawback, solvent evaporation-induced self-assembly approach can be used, and film or monolith can result [8-11]. The second pathway is based on a cooperative self-assembly of low concentrated surfactant and a silica source to form the mesostructured material by precipitation, this method yields only powders, and large quantities can be made.

The chemical functionalization of the mesoporous silicas is critical since it opens the door to a wide range of applications. The incorporation of organic functional groups into mesoporous silicas can be done through covalent and noncovalent approaches [12-15]. In this regard, covalent functionalization via silane chemistry is the most widespread and can be accomplished through both direct (co-condensation) and indirect (postsynthetic grafting) methods [1]. The cocondensation method consists in the co-polymerization of an organo-silane and a silica source in 
the presence of a structure directing agent. Hence, organic functionalities are part of the silica matrix and homogenously distributed in the mesopores [16-18]. However, the pore ordering degrades with increasing concentration of organic groups, which ultimately leads to totally disordered products. Consequently, the functional groups loading is limited to $25 \%$ [19]. In the post-synthetic grafting method, organic groups are attached onto the pore surface by the reaction of organosilanes subsequent to the silica synthesis[20]. This very general method of modification does not permit the control of the loading and can lead to a nonhomogeneous distribution of the organic groups within the pores and in extreme cases to complete closure of the pores[21]. Nevertheless, by this method, large biologic molecules including dendrimers [22, 23], enzymes [24] and polypeptides [25] have been incorporated into ordered mesoporous silicas (OMS) by further functionalization of small functional groups such as amines, thiols, alkyl halides or alkenes. In terms of the production cost, the one-pot synthesis is more advantageous than the post-synthetic grafting method.

A large domain of synthesis of OMS is the preparation of polymer/silica composites since they present a broad spectrum of applications [26]. This enabled the study of both the behavior of macromolecular building blocks confined in the pores and the polymerization in nano-confined environments [27]. Non-covalent or covalent methods can be implemented to functionalize mesoporous silicas with polymers. Non-covalent method consists in an immobilization of the polymer onto the nanoporous materials by using wet impregnation methods whereas covalent anchoring on the surface can be accomplished by either co-condensation, "grafting to" and "grafting from" approaches. The co-condensation method consits in a polymerization of silica precursor such as tetraethoxysilane (TEOS) or tetramethoxysilane (TMOS) and a copolymer bearing containing alkoxysilane groups. There was only few examples of polymers functionalized OMS prepared by co-condensation method. Feng et al. have reported the synthesis of a 
polystyrene-silica hybrid mesoporous materials by co-condensation of tetraethyl orthosilicate (TEOS) with poly(styrene-co-styrylethyl trimethoxysilane) using dibenzoyl tartraric acid as nonsurfactant template [28]. The hybrid materials exhibit high surface area and pore volume with small pore diameters of $\sim 2-4 \mathrm{~nm}$, however TEM image of mesoporeous material showed no identifiable structural order. $\mathrm{Fu}$ et al. have synthesized the ordered mesoporous silice/poly(Nisopropylacrylamide (PNIPAM) copolymer composites by co-condensation of TEOS and PNIPAM-co-poly(3-methacryloyloxypropyltrimethoxysilane) in the presence of surfactant [29]. The authors did not studied the mesostructure (surface area, pore volume and pore size) of PNIPAM/silica hybrid materials. The common point of these studies was the alkoxysilane groups are distributed along the copolymer chain that could lead to an embeding of polymer chain in the wall of OMS during the formation of silica networks. "Grafting to" is the anchoring of a silylated polymer onto the surface of the mesoporous silica. This method usually generated nongrafted chains. In addition, the grafted chains prevent attachement of the next ones and then limit the grafting density [30]. The "grafting from" method is based on the growth of the polymer chains from the initiator-modified mesopore surface, predominantly through controlled radical polymerization such as reversible addition-fragmentation chain transfer polymerization (RAFT) [31-33], atom transfer radical polymerization (ATRP) [34-37], and nitroxide-mediated radical polymerization (NMP) [38-40]. The use of metallic catalyst and organic ligands in ATRP technique is considered as a disadvantage compared to the other techniques. Although the "grafting from" method allows to achieve grafting of various polymer chains of controlled molecular weight and low dispersity to mesoporous silica surface however, in some cases, the polymer filled the entire volume of the silica mesopores, leading to quasi-nonporous materials with very low activity of polymer organic groups. Furthermore, the initiator is grafted to silica surface via post-modification after the synthesis of OMS. The initiator and thus the polymer chains can be found both inside and outside pores surface. 
To overcome the main drawback of methods described in the literature, we propose in the present article an alternative synthesis route toward polymer-silica mesoporous materials. Our approach is based on an adaptation of the sol-gel process by direct synthesis in which a block copolymer, poly(ethylene oxide)-b-polystyrene (SEO), used as structure directing agent, is designed to exhibit a good affinity with a functional polymer bearing triethoxysilane end-group (Figure 1). The novelty of this strategy resides in the formation of micelles in aqueous medium, with a core composing of polystyrene and functional polymer surrounded by a shell of poly(ethylene oxide). The silica precursors can thus co-condensate around this supramolecular structure. By this approach, the SEO template is eliminated by extraction, mesoporous silica with well-defined, accessible functional polymer homogenously distributed inside the pores channels were obtained. By controlling the functional polymer loading and their molar mass, polymermesoporous silica with different morphologies were synthesized. The resulting functionalized polymer mesoporous silica were evaluated for $\mathrm{CO}_{2}$ capture. On the other hand, utilization of mesoporous silica impregnated or tethered with active group such as alkyl-amines for $\mathrm{CO}_{2}$ capture was well known and widely reported in the literature [3, 41-44]. Among polymer/mesoporous silica composites used for $\mathrm{CO}_{2}$ capture, polymeric amine-functionalized silica sorbents were the most studied [45]. However, they are subject to oxidation degradation in the presence of dioxygen [4650]. The degraded products of amine-functionalized silicas have been found to be compounds containing $\mathrm{C}=\mathrm{O}, \mathrm{N}=\mathrm{O}$ and $-\mathrm{CH}=\mathrm{N}$ - species $[48,51,52]$. In addition, the amine degradation products include nitrosamines may cause environmental and health problems.

In the aim to develop new efficient hybrid materials for $\mathrm{CO}_{2}$ capture, functional polymers bearing reactive groups such as $\mathrm{NO}_{2}$, and $\mathrm{N}\left(\mathrm{CH}_{3}\right)_{2}$ were prepared in order to synthesize functional OMS and their adsorption capability was studied in the present work. The relationship between 
sorbent structure-and $\mathrm{CO}_{2}$ capture properties will be investigated since the recent studies highlighted the key role of these parameters $[53,54]$.

\section{(Figure 1)}

\section{Experimental section}

\subsection{Materials}

Tetraethyl orthosilicate (TEOS, 98\%), 3-aminipropyl triethoxysilane (APS, 99\%), styrene (S, 99\%), 4-vinylbenzyl chloride (VBC, 90\%), N,N-dimethylacrylamide (DMA, 99\%), NaN3 $(>99.5 \%)$, tetrahydrofuran, ethanol were purchased from Aldrich. BlocBuilderMA ${ }^{\circledR}(>99 \%)$, an

alkoxyamine based on the nitroxide SG1 (N-tert-butyl- $N$-[1-diethylphosphono-(2,2dimethylpropyl)] nitroxide) and the 1-carboxy-1-methylethylalkyl moiety was kindly provided by Arkema (France). MAMA-NHS, an alkoxyamine bearing the activated carboxylic function was prepared from the BlocBuilderMA ${ }^{\circledR}$ following the method reported by Vinas et al. [55]. Amphiphilic block copolymer, poy(ethylene oxide)-b-polystyrene (called SEO), was synthesized by nitroxide mediated polymerization (NMP) of styrene using PEO-macroalkoxyamine as initiator as previously reported [8]. Two SEO block copolymers were used, both composing of PEO of 5000 $\mathrm{g} \mathrm{mol}^{-1}$ with PS block of 3000 (SEO1) or 5000 (SEO2) g mol ${ }^{-1}$. 4-nitrostyrene (NS) was synthesized according to the works of Schmidt et al. [56]. All solvents and other reagents were synthesis grade and used without further purification.

\subsection{Synthesis of polystyrene-based polymers}

Synthesis of polystyrene (PS), poly(4-nitrostyrene-CO-styrene) (P(NS-CO-S)) and poly $(N, N$ dimethylacrylamide-co-styrene) (P(DMA-co-S)) were performed using NMP. Typically, styrene, co-monomers and MAMA-NHS were dissolved in a given volume of ethylbenzene to generate a 
mixture containing $65 \mathrm{wt} \%$ of monomers. The mixture was then loaded in a three-neck flask equipped with a reflux condenser and a magnetic stir bar, purged with argon for $20 \mathrm{~min}$ at room temperature to remove dioxygen. Polymerization was performed at $120^{\circ} \mathrm{C}$ for 180 min under argon atmosphere. The crude product was poured into a large excess of cold pentane to precipitate the copolymer. The copolymer was then isolated by filtration and dried under vacuum at room temperature to a constant weight. The experimental data of these synthesis are summarized in Table 1.

(Table 1)

\subsection{Synthesis of triethoxysilane functionalized polystyrene-based copolymers}

In a typical experiment, $1 \mathrm{~g}$ of PS or PS-based copolymers such as P(NS-co-S) and P(DMACo-S), previously synthesized was introduced into a round bottom flask and dried at $100^{\circ} \mathrm{C}$ under reduced pressure for $15 \mathrm{~min}$ to eliminate all traces of water. The copolymer was dissolved with 20 $\mathrm{mL}$ of distilled dichloromethane under Ar atmosphere, and then APS (5 eq relative to terminal activated carboxylic group) were added to the solution via a syringe. After $2 \mathrm{~h}$ of reaction at room temperature, the copolymer solution was filtered through $0.45 \mu \mathrm{m}$ Millipore filter and precipitated in cold pentane to isolate the functional copolymer. The copolymer was dried and stored at room temperature under Ar atmosphere until use.

\subsection{Synthesis of silica-based mesoporous polymeric-inorganic hybrid materials}

Two processes were used for the synthesis of mesoporous silica. The first one is evaporationinduced self-assembly (EISA) and the second process is cooperative self-assembly (or precipitation). In a typical synthesis, $500 \mathrm{mg}$ of SEO block copolymer and $100 \mathrm{mg}$ (or $50 \mathrm{mg}$ ) of triethoxysilane functionalized copolymer were dissolved in $4 \mathrm{~mL}$ of $\mathrm{THF}$ at $40^{\circ} \mathrm{C}$. Under vigorous agitation, $2 \mathrm{~mL}$ of $\mathrm{HCl}$ at $\mathrm{pH} 2$ or $22 \mathrm{~mL}$ of $\mathrm{HCl}$ solution at $2 \mathrm{M}$ were added dropwise to the previous 
mixture according to the EISA or precipitation processes respectively. Then a mixture of $1 \mathrm{~g}$ of TEOS and $0.5 \mathrm{~g}$ of ethanol was added. Stirring was continued until gelation or precipitation of the product. The as-formed clear gel was aged for three days at room temperature and then $48 \mathrm{~h}$ at $40^{\circ} \mathrm{C}$ while the solid suspension obtained from the precipitation process was aged for $24 \mathrm{~h}$ at $40^{\circ} \mathrm{C}$ and then at $100^{\circ} \mathrm{C}$ for $48 \mathrm{~h}$. Finally, the block copolymer template was removed by soxhlet extraction in THF for 2 days. The silica materials were dried at $100^{\circ} \mathrm{C}$ for $24 \mathrm{~h}$ and stored in ambient air. In order to investigate the correlation between materials morphologies and loading functional copolymer as well as the materials performance for $\mathrm{CO}_{2}$ capture, different samples were synthesized, which were denoted P@MS_Cx, where P represents the nature of grafted functional polymer, and $\mathrm{Cx}$ is the quantity of triethoxysilane functionalized (co)polymer used in the synthesis of mesoporous silica (MS) with $\mathrm{x}=1$ corresponding to $50 \mathrm{mg}$ of functionalized copolymer and $\mathrm{x}$ $=2$ corresponding to $100 \mathrm{mg}$ of functionalized copolymer. $\mathrm{P}=\mathrm{S}, \mathrm{NO}_{2}$ and DMA designated $\mathrm{MS}$ functionalized with PS, (P(NS-Co-S)) and P(DMA-Co-S) respectively. Experimental conditions for the synthesis of functionalized mesoporous silicas are summarized in Table 2.

\section{(Table 2)}

\subsection{Characterization techniques}

${ }^{1} \mathrm{H}$ NMR spectra in $\mathrm{CDCl}_{3}$ were recorded on a Bruker Advance 400 spectrometer. Chemical shift was given in ppm relative to tetramethylsilane.

All solid-state Cross Polarization Magic Angle Spinning (CP MAS) NMR spectra were obtained on a Bruker Avance-400 MHz NMR spectrometer operating at a ${ }^{13} \mathrm{C}$ and ${ }^{29} \mathrm{Si}$ resonance frequency of $101.6 \mathrm{MHz}$ and $79.5 \mathrm{MHz}$, respectively. ${ }^{13} \mathrm{C}$ and ${ }^{29} \mathrm{Si} \mathrm{CP}$ MAS experiments were performed with a commercial Bruker Double-bearing probe. About $100 \mathrm{mg}$ of samples were placed 
in zirconium dioxide rotors of 4-mm outer diameter and spun at a Magic Angle Spinning rate of 10 $\mathrm{kHz}$. The ${ }^{13} \mathrm{C}$ and ${ }^{29} \mathrm{Si}$ chemical shifts were referenced to tetramethylsilane.

Polymer molecular weights and dispersities were determined by size exclusion chromatography (SEC). The used system was an EcoSEC (Tosoh, Japan) equipped with a PL Resipore Precolumn (4.6 x $50 \mathrm{~mm}$, Agilent) and two linear M columns (4.6 x $250 \mathrm{~mm}$, Agilent) with a gel particle diameter of $3 \mu \mathrm{m}$. These columns were thermostated at $40^{\circ} \mathrm{C}$. Detection was made by an UV/visible detector operated at $\lambda=254 \mathrm{~nm}$, a dual flow differential refractive index detector, both from Tosoh, and a viscometer ETA2010 from PSS. Measurements were performed in THF at a flow rate of $0.3 \mathrm{~mL} \mathrm{~min}^{-1}$. Calibration was based on polystyrene standards from Polymer Laboratories (ranging from $370 \mathrm{~g} \mathrm{~mol}^{-1}$ to $371100 \mathrm{~g} \mathrm{~mol}^{-1}$ ).

Dynamic Light Scattering (DLS) measurements were performed on a Malvern Nanosizer ZSapparatus equipped with a He-Ne laser operating at a wavelength of $633 \mathrm{~nm}$ and working at a fixed angle of $117^{\circ}$. The temperature was controlled at $25^{\circ} \mathrm{C}$. Each analysis was repeated three time to give the average particle size.

The thermal degradation of the hybrid silica-polymer material was investigated by Thermogravimetric Analysis (TGA Q500, TA Instruments), performed between 25 and $800{ }^{\circ} \mathrm{C}$ with a maximum heating rate of $5 \mathrm{~K} \mathrm{~min}^{-1}$ under dynamic air atmosphere (sample flow rate $40 \mathrm{~mL} \mathrm{~min}$ ${ }^{1}$ ) in platinum sample holders.

The $\mathrm{N}_{2}$ adsorption-desorption isotherms were obtained at $77 \mathrm{~K}$ on a Micrometrics ASAP 2010. The specific surface area was determined with the Brunauer, Emmet and Teller (BET) method and the pore size distribution was calculated from the adsorption isotherms using the Barrett-JoynerHalenda (BJH) method. Prior to adsorption, samples were outgassed at $393 \mathrm{~K}$ overnight under a residual vacuum pressure of $2.10^{-3}$ mbar. 
Silicas for TEM measurements were embedded in epoxy resin. Samples were prepared using ultramichrotomy techniques and then deposited on copper grids. TEM measurements were carried out at $120 \mathrm{kV}$ with a JEOL 1200 EXII microscope.

SAXS experiments were performed on SAXSess-MC2 (Anton-Paar, GmbH, Austria) with a sealed copper tube as X-ray source (wavelength is $0.15417 \mathrm{~nm}(\mathrm{Cu} \mathrm{K}-\alpha)$ ) and CCD camera as detection system.

\subsection{Gas adsorption measurements}

The gas adsorption measurements at $303 \mathrm{~K}$ and up to 25-30 bars were made with $\mathrm{CO}_{2}, \mathrm{CH}_{4}$, and $\mathrm{N}_{2}$ using a homemade high-throughput instrument [57]. Gas adsorption is measured via a manometric gas dosing system on six samples in parallel. The amounts of gas adsorbed are calculated by an equation of state using the Reference Fluid Thermodynamic and Transport Properties (REFPROP) software package 8.0 of the National Institute of Standards and Technology (NIST) [58]. Around $100 \mathrm{mg}$ of sample is used, and each sample can be thermally activated individually in situ under primary vacuum, at a $393 \mathrm{~K}$ overnight. The gases were obtained from Air Liquide. Nitrogen and methane were of $99.9995 \%$ purity (N55), carbon dioxide was of $99.995 \%$ purity (N45).

\section{Results and Discussion}

\subsection{Synthesis of functional (co)polymers.}

Several well-defined functional polystyrene based copolymers bearing triethoxysilane end group were synthesized in two steps. The first step was the nitroxide-mediated polymerization (NMP) of styrene and functional monomer using MAMA-NHS as initiator and the second step was the coupling reaction between the obtained functional copolymer and 3-aminopropyl 
triethoxysilane (APS) (Scheme 1). The molar mass of these copolymers was between 2200 and $3200 \mathrm{~g} \mathrm{~mol}^{-1}$, determined by size exclusion chromatography (SEC) and their dispersity was quite low $(\mathrm{Ð}<1.3)$. The molar composition of these copolymers, determined by ${ }^{1} \mathrm{H}$ NMR, was 44 and $26 \mathrm{~mol} \%$, of 4-nitrostyrene and dimethylacrylamide respectively. The characterization data of used functional copolymers for the synthesis of mesoporous silicas are listed in Table 1.

(Scheme 1)

The sol-gel process by direct synthesis was selected to prepare hybrid mesoporous silicas. Preliminary investigation showed that standard structure-directing agent Pluronic123 (P123) was unsuitable for incorporating these functional polymers into P123 micelles. In order to overcome this key point for the success of the sol-gel process and to maximize the affinity of functional polymers with the structure-directing agent, two diblock copolymers were designed. Both were built from a common hydrophilic PEO of $5000 \mathrm{~g} \mathrm{~mol}^{-1}$ that covalently links to hydrophobic PS block with two molar masses of 3000 and $5000 \mathrm{~g} \mathrm{~mol}^{-1}$, called SEO1 and SEO2 respectively. Before processing to the preparation of hybrid silicas, we checked the miscibility of the mixture of SEO1 amphiphilic copolymer and functional polymer bearing triethoxysilane end-group in aqueous medium. For that, SEO1 copolymer and functional polymer were dissolved in THF at the same ratios as used in the synthesis of silica. Under vigorous stirring, acidic water $(\mathrm{pH}=2)$ was then added to this solution which underwent micellization forming a supramolecular structure. Micelles size of solution prepared with and without the presence of functional polymers was measured by dynamic light scattering (DLS). We observed an increase of micelles size when the SEO1 diblock copolymer was dissolved in $\mathrm{THF} / \mathrm{H}_{2} \mathrm{O}$ with the presence of 10 or 20 wt.\% of poly(styrene-co-nitrostyrene) (Figure S1). This result indicates that functional polymer was incorporated in the core of SEO1 micelles. Similar results were also observed for PS and P(DMA- 
co-S) (co)polymers (not presented here). These PEO-based systems were then used as structuredirecting agents for the synthesis of silica under acidic conditions.

\subsection{Influence of synthesis conditions on the composition and the mesostructure of hybrid silica}

All mesoporous hybrid silicas were characterized by TGA and solid-state ${ }^{13} \mathrm{C}$ and ${ }^{29} \mathrm{Si} \mathrm{CP} \mathrm{MAS}$ NMR to determine their composition and structure while their mesoporous structures were analyzed by TEM, SAXS and $\mathrm{N}_{2}$ adsorption. Quantitative determination of organic content by TGA showed that the extraction of SEO1 and SEO2 amphiphilic copolymer template was not complete from silica matrix (similar to residual P123 in SBA-15 synthesis), particularly in DMA@MS_C2 sample (Figure 2a). Three weight losses were observed on all TGA diagrams, the first one until $120^{\circ} \mathrm{C}$ corresponds to physisorbed species (water, solvent), the second one between $180-500^{\circ} \mathrm{C}$ corresponds to the decomposition of functional polymer and the last one above $500^{\circ} \mathrm{C}$ is attributed to the loss of PEO-b-PS copolymer template. It was demonstrated that for most assemblies of nonionic amphiphiles such as PEO- $b$-PS with $\mathrm{M}_{n}$ PEO significantly higher than $\mathrm{M}_{n}$ PS, PEO contributes to both the meso- and micropores [59]. It suggests that the PEO chains are partially dissolved in the inorganic phase during the sol-gel process and embedded in the silica walls. For this reason, the decomposition of the remaining copolymer template occurred at temperatures higher than that of functional polymer. The total weight loss of functional (co)polymers inside hybrid MS at $500^{\circ} \mathrm{C}$ is reported in Table 2. From this data and knowing the weight ratio of functional copolymer (Table 1), we can calculate the content of styrene and comonomer (nitrostyrene or $\mathrm{N}, \mathrm{N}$-dimethylacrylamide) incorporated in mesoporous silica (Table 2).

To compare the influence of the synthesis protocol on the composition and mesostructure of hybrid MS, two processes were used namely EISA and precipitation. Polystyrene and poly(styreneco-nitrostyrene) copolymer were used as functional polymer (Table 2, entries 1, 2, 4 and 6). Figure 
$2 \mathrm{~b}$ shows the TGA thermograms of PS and $\mathrm{P}(\mathrm{NS}-\mathrm{CO}-\mathrm{S})$ functionalized MS prepared by EISA and precipitation processes respectively. At the same loading quantity of polymer, one can see that EISA process allows to graft more functional polymer than the precipitation process. We can explain this by the difference in functional polymer concentration in the mixture. Indeed, the concentration of functional polymer was lower in the mixture of precipitation process than the EISA; in addition, all polymer chains did not co-precipitate during silica formation and hence they were eliminated by filtration.

(Figure 2)

On the other hand, by using EISA process and the same loading quantity of functional polymer, the grafting amount of these polymers increases as PS $<\mathrm{P}(\mathrm{NS}-\mathrm{Co}-\mathrm{S})<\mathrm{P}(\mathrm{DMA}-\mathrm{Co}-\mathrm{S})$ (Figure 2a). This suggests that the hydrophilic character of functional polymers improves their incorporation or grafting to MS. Furthermore, increase of loading quantity of functional polymers in the sol-gel process led to a hybrid MS with high grafting amount (Table 2, entries 4, 5, 8 and 9), however the specific surface area of the resulting hybrid MS dramatically decreased (Table 3, entries 5, 9 and 10). Employing a high functional polymer concentration can engender pore obstruction. In contrast to the EISA process, the precipitation process led to a hybrid MS with high specific surface area whatever the nature of functional polymer and their loading concentration (Table 3, entries 2, 3, 6 and 7) though the grafting quantity of functional polymer was lower than $20 \mathrm{wt} \%$ in any cases. In summary, whatever the process used, we have successfully grafted high quantities of functional polymer to MS with quite high specific surface area (S $\mathrm{BET}$ ), however the value of $\mathrm{S}_{\mathrm{BET}}$ became low when the quantity of grafted polymer exceeded $20 \mathrm{wt} \%$.

Solid state ${ }^{13} \mathrm{C}$ and ${ }^{29} \mathrm{Si}$ MAS NMR analysis provided structural information on the hybrid materials. Indeed, the ${ }^{13} \mathrm{C} \mathrm{CP}$ MAS NMR spectrum of $\mathrm{NO}_{2} @ \mathrm{MS} \_\mathrm{C} 2$ hybrid silica (Figure 3a) 
displayed two characteristic peaks at $126 \mathrm{ppm}$ and $146 \mathrm{ppm}$ attributed to aromatic carbon of styrene and nitrostyrene units respectively. On the other hand, we also observed the presence of a small peak of PEO (- $\left.\mathrm{CH}_{2}-\mathrm{CH}_{2}-\mathrm{O}-\right)$ at $70 \mathrm{ppm}$, confirming an incomplete extraction of template copolymer already stated by TGA analysis. Solid state ${ }^{29}$ Si MAS NMR provides information about silicon environment. The ${ }^{29} \mathrm{Si}$ MAS NMR spectrum of $\mathrm{NO}_{2} @ \mathrm{MS} \_\mathrm{C} 2$ hybrid silica (Figure 3b) shows two kinds of siloxane bonds, Q and T. The obtained hybrid silica exhibits a major peak at 100.6 ppm corresponding to $\mathrm{HOSi}(\mathrm{OSi})_{3}\left(\mathrm{Q}^{3}\right)$ silicate species as well as two additional resonances at -91.5 and $-109.7 \mathrm{ppm}$ corresponding to $(\mathrm{HO})_{2} \mathbf{S i}(\mathrm{OSi})_{2}\left(\mathrm{Q}^{2}\right)$ and $\mathbf{S i}\left(\mathrm{OSi}_{4}\left(\mathrm{Q}^{4}\right)\right.$ respectively. Since the material is functional silica, the ${ }^{29} \mathrm{Si} \mathrm{MAS} \mathrm{NMR} \mathrm{spectrum} \mathrm{showed} \mathrm{also} \mathrm{other} \mathrm{resonances}$ at -57 and $65.3 \mathrm{ppm}$ that were assigned to $\mathrm{R}-\mathrm{Si}(\mathrm{OH})(\mathrm{OSi})_{2}\left(\mathrm{~T}^{2}\right)$ and $\mathrm{R}-\mathrm{Si}-(\mathrm{OSi})_{3}\left(\mathrm{~T}^{3}\right)$ centers, respectively. These results suggest that the functional (co)polymer was covalently anchored to silica pores wall. Similar results were obtained for all hybrid silicas studied in this paper.

(Figure 3)

\subsection{Mesostructure characterization of hybrid materials.}

All silicas made from SEO1 template in the presence of functional (co)polymers were mesoporous materials as shown by TEM images in Figure 4. These TEM images highlighted a homogenous pore structure for three silicas in-situ functionalized with different functional (co)polymers. However, a minor structural difference was observed in the mesopore system according to synthesis conditions. For example, two materials functionalized with the same functional (co)polymer, the sample made with precipitation process $\left(\mathrm{NO}_{2} @ \mathrm{MS} \_\mathrm{C} 1-\mathrm{p}\right)$ appeared more ordered than the one prepared by EISA process ( $\left.\mathrm{NO}_{2} @ \mathrm{MS} \_\mathrm{C} 1\right)$ (Figures 4a and b). 
(Figure 4)

The nitrogen adsorption-desorption isotherms at $77 \mathrm{~K}$ on $\mathrm{NO}_{2} @ \mathrm{MS} \_\mathrm{C} 1$ hybrid silica series as a representative example are shown in Figure 5. Despite a steep slope at low relative pressures in the adsorption branch, suggesting the presence of some micropores, the shape of these adsorptiondesorption isotherms, with a systematic plateau observed for each from $\mathrm{p} / \mathrm{p}^{\circ}$ around 0.7 up to 1 , corresponds to a type IV isotherm according to IUPAC classification, indicating that the samples mainly contains mesopores. The equivalent surface areas were calculated using BET method and the values are given in Table 3 along with estimation of the micropore volumes determined from the t-plot method. The samples exhibited quite high BET surface areas and their values decreased with the grafting quantity of functional polymers. Regarding the desorption branches of the curves, all samples show hysteresis which are generally related to the pore shape. Their common feature is the closure of the hysteresis loop at a relative pressure around 0.45 revealing mesopores with small entrances. Moreover, a specific desorption branch with a double step is observed for samples $\mathrm{NO}_{2} @ \mathrm{MS} \_\mathrm{C} 1$ and $\mathrm{NO}_{2} @ \mathrm{MS} \_\mathrm{C} 1 \_\mathrm{SEO} 2$, which may be interpreted by a distribution of mesopores with a same internal width but either with two different sizes for the entrances or with interconnections between the pores [8].

(Figure 5)

(Table 3)

Figure S2 shows the I(q) SAXS diffractograms obtained for different polymer functionalized MS materials. Almost of these scattering curves display only a single broad peak located around $0.4-0.6 \mathrm{~nm}^{-1}$, characteristic of a wormlike structure. For each MS sample, the characteristics period, $d=2 \pi / q_{\max }$, of the mesostructured can be extracted from the peak position $\left(q_{\max }\right)$. All 
samples possess a mesopore period between $12.8 \mathrm{~nm}$ and $14.7 \mathrm{~nm}$. From SAXS analysis, it can be underlined different points: a) the chemical nature of the functional polymer has no incidence on the mesostructure of samples, while their concentration does, b) whatever the processes used, EISA vs precipitation, almost all samples exhibit the same inter pore distance, c) it seems important that functional polymers should have similar $M_{n}$ as the PS block of the structure-directing agent, here is $3000 \mathrm{~g} \mathrm{~mol}^{-1}$, so they can be easily incorporated to MS materials.

\subsection{Gas adsorption performance of hybrid silica}

Pure silica surfaces, owing naturally residual hydroxyl groups, do not provide strong adsorption sites to interact with $\mathrm{CO}_{2}$. However, modification of mesoporous silica with silanesand polymer- containing amino groups enhanced adsorption and separation towards $\mathrm{CO}_{2}$ [60-62]. The $\mathrm{CO}_{2}$ adsoption properties of the hybrid silicas were evaluated by measuring adsorption isotherms and the $\mathrm{CO}_{2}$ adsorption amounts at $30^{\circ} \mathrm{C}$ and at 22 bars are summarized in Table 3. In this work, the best adsorption, regarding the amount adsorbed and the selective properties for the $\mathrm{CO}_{2}$, is observed for the $\mathrm{NO}_{2} @ \mathrm{MS} \_\mathrm{C} 1-\mathrm{p}, \mathrm{NO}_{2} @ \mathrm{MS} \_\mathrm{C} 2-\mathrm{p}$ and $\mathrm{NO}_{2} @ \mathrm{MS} \_\mathrm{C} 1-\mathrm{SEO} 2$ samples (Table 3, entries 6-8). In these materials, each $\mathrm{NO}_{2}$ group can adsorb in average between 4 - $8 \mathrm{CO}_{2}$ molecules (Table 3). The combination of the high specific surface areas and the $\mathrm{NO}_{2}$ groups accessible as attractive sites can explain these gas adsorption performances. One can note that the increase in functional polymer grafted content can partially block the pore channels and hence the decrease of the accessibility of active groups, leading to a reduction of adsorption performance. Figure 6 presents a comparison of the gas $\left(\mathrm{CO}_{2}, \mathrm{~N}_{2}\right.$ and $\left.\mathrm{CH}_{4}\right)$ adsorption isotherms performed on $\mathrm{NO}_{2} @ \mathrm{MS} \_\mathrm{C} 1-\mathrm{SEO} 2$. The adsorption isotherms were measured at room temperature $(303 \mathrm{~K})$ as a function of gas equilibrium pressure. Functionalized hybrid silica shows higher affinity towards carbon dioxide compared to nitrogen and methane. Therefore thanks to these pure component adsorption isotherms, the $\mathrm{CO}_{2} / \mathrm{CH}_{4}$ and $\mathrm{CO}_{2} / \mathrm{N}_{2}$ selectivities, or separation factors were roughly 
estimated by a simple calculation of the ratio of the amount of $\mathrm{CO}_{2}$ adsorbed divided by the amount of $\mathrm{CH}_{4}$ and $\mathrm{N}_{2}$ adsorbed at a given pressure $(1 \mathrm{bar})$ and $30^{\circ} \mathrm{C}$. In this manner for this sample, the separation factor at 1 bar was 8.1 and 32.3 for $\mathrm{CO}_{2} / \mathrm{CH}_{4}$ and $\mathrm{CO}_{2} / \mathrm{N}_{2}$ respectively. Whilst not as high as for amine grafted materials, this does reveal that the $\mathrm{CO}_{2}$ molecules interact preferentially with the accessible $\mathrm{NO}_{2}$ groups in the hybrid material. The simulated $\mathrm{CO}_{2} / \mathrm{CH}_{4}$ separation factor is comparable with the value found in the litterature for a hybrid adsorbent system composing of zeolite 5A pellets and FAU-zeolite.[63] The maximum separation factor of this hybrid zeolite membrane for $\mathrm{CO}_{2} / \mathrm{CH}_{4}$ was 5.72 at $313 \mathrm{~K}$ and at 1.5 bar. Liu et al. have obtained remarkable selectivity in the separation of $\mathrm{CO}_{2} / \mathrm{N}_{2}$ gas mixture using amine-functionalized mesoporous silica @ reduced graphene sandwichlike structure materials [64]. The $\mathrm{CO}_{2} / \mathrm{N}_{2}$ separation factor of 47.6 at $0^{\circ} \mathrm{C}$ and at 1 bar was found for these systems.

(Figure 6)

The $\mathrm{CO}_{2}$ adsorption is progressive and mainly takes place at the surface of the material at 303 $\mathrm{K}$ and on the whole pressure domain used in the measurements (0-30 bars). Then, this surface process can suggest to represent the maximum amount of $\mathrm{CO}_{2}$ adsorbed at a given pressure (22 bars) as a function of BET specific surface area ( $\left.\mathrm{S}_{\mathrm{BET}}\right)$ for different hybrid silicas. Indeed this comparison, given in Figure 7, highlights that for all the $\mathrm{NO}_{2} @ \mathrm{MS}$ samples the $\mathrm{CO}_{2}$ adsorbed increase with the SBET, and for a similar SBET, MS functionalized with P(NS-Co-S) interacts stronger with $\mathrm{CO}_{2}$ than PS.

(Figure 7)

\section{Conclusions}

In this work, we presented an alternative synthesis route toward polymer-silica mesoporous materials through the co-condensation of silica precursor (TEOS) and a functional polymer with 
triethoxysilane end-group in the presence of a tailored PEO-b-PS amphiphilic copolymer as pore template. The novelty of this strategy resides in the preparation of a miscible blend of PEO- $b$-PS amphiphilic copolymer and triethoxysilane functional polymer bearing $-\mathrm{NO}_{2}$ or $-\mathrm{N}\left(\mathrm{CH}_{3}\right)_{2}$ groups. In aqueous medium, this mixture undergoes micellization forming a supramolecular structure around which the silica precursors can co-condensate. Once the amphiphilic diblock copolymer is eliminated by extraction, polymer functionalized mesoporous silicas were obtained. By controlling the functional polymer loading and process conditions, this new approach allowed to prepare ordered polymer-mesoporous silicas with high polymer content, up to $20 \mathrm{wt} \%$, high specific surface area and large pores.

The gas adsorption results clearly showed the potential of $\mathrm{NO}_{2} @ \mathrm{MS}$ materials in separation applications. Indeed, from an applications perspective, a search for alternative functions to the most widely studies amine derivatives are of interest. This is light of the oxidative degradation of amines to which can form cancerous nitrosamines or other species that can equally be environmentally questionable. The materials developped int this work show high stability, significant $\mathrm{CO}_{2}$ uptake and interaction as well as promising $\mathrm{CO}_{2} / \mathrm{N}_{2}$ separation potential.

\footnotetext{
ASSOCIATED CONTENT

Electronic Supporting Information

Dynamic light scattering curve of PEO-b-PS diblock copolymer and its mixture with poly(styreneco-nitrostyrene) in aqueous medium and small angle scattering X-ray curves of different polymer functionalized mesoporous silicas. These materials are available free of charge online at the Elsevier Publications website.
} 


\title{
AUTHOR INFORMATION
}

\author{
Corresponding Authors
}

* Trang N. T. Phan: trang.phan@univ-amu.fr, Eric Besson: eric.besson@univ-amu.fr

\author{
Present Addresses
}

$\S$ TOTAL SE, Centre Scientifique et Technique Jean Féger, Pau, France.

\section{Author Contributions}

The manuscript was written through contributions of all authors. All authors have given approval to the final version of the manuscript.

\section{REFERENCES}

[1] F. Hoffmann, M. Cornelius, J. Morell, M. Fröba, Silica-based mesoporous organic-inorganic hybrid materials, Angew. Chem. Int. Ed., 45 (2006) 3216-3251.

[2] B.P. Bastakoti, Y. Li, N. Miyamoto, H. Abe, J. Ye, S. Pavuluri, Y. Yamauchi, Polymeric Micelle Assembly for Direct Synthesis of Functionalized Mesoporous Silica with Fully Accessible Pt Nanoparticles toward Improved CO Oxidation Reaction, Chem. Comm., 50 (2014) 9101-9104.

[3] J.C. Hicks, J.H. Drese, D.J. Fauth, M.L. Gray, G. Qi, C.W. Jones, Designing adsorbents for $\mathrm{CO}_{2}$ capture from flue gas-hyperbranched aminosilicas capable of capturing $\mathrm{CO}_{2}$ reversibly, J. Am. Chem. Soc., 130 (2008) 2902-2903.

[4] D. Niu, Z. Liu, Y. Li, X. Luo, J. Zhang, J. Gong, J. Shi, Monodispersed and ordered large-pore mesoporous silica nanospheres with tunable pore structure for magnetic functionnalization and gene delivery, Adv. Mater., 26 (2014) 4947-4953.

[5] A. Birault, E. Molina, G. Toquer, P. Lacroix-Desmazes, N. Marcotte, C. Carcel, M. Katouli, J. Bartlett, C. Gérardin, M. Wong Chi Man, LargePore Periodic Mesoporous Organosilicas as Advanced Bactericide Platforms, ACS Appl. Bio Mater., 1 (2018) 1787-1792.

[6] Y. Wan, D.Y. Zhao, On the controllable soft-templating approach to mesoporous silicates, Chem. Rev., 107 (2007) 2821-2860.

[7] G.J.A.A. Soler-Illia, O. Azzaroni, Multifunctional hybrids by combining ordered mesoporous materials and macromolecular building blocks, Chem. Soc. Rev., 40 (2011) 1107-1150.

[8] E. Bloch, L.P. Llewellyn, T. Phan, D. Bertin, V. Hornebecq, On Defining a Simple Empirical Relationship to Predict the Pore Size of Mesoporous Silicas Prepared from PEO-b-PS Diblock Copolymers, Chem. Mater., 21 (2009) 48-55.

[9] J. Wei, H. Wang, Y. Deng, Z. Sun, L. Shi, B. Tu, M. Luqman, D. Zhao, Solvent evaporation induced aggregating assembly approach to threedimensional ordered mesoporous silica with ultralarge accessible mesopores, J. Am. Chem. Soc., 133 (2011) 20369-20377.

[10] J.-G. Li, Y.-D. Lin, S.-W. Kuo, From Microphase Separation to Self-Organized Mesoporous Phenolic Resin through Competitive Hydrogen Bonding with Double-Crystalline Diblock Copolymers of Poly (ethylene oxide-b-caprolactone), Macromolecules, 44 (2011) 9295-9309.

[11] J. Wei, Q. Yue, Z. Sun, Y. Deng, D. Zhao, Synthesis of Dual-Mesoporous Silica Using Non-Ionic Diblock Copolymer and Cationic Surfactant as Co-Templates, Angew. Chem. Int. Ed., 51 (2012) 6149-6153.

[12] K. Moller, T. Bein, Inclusion chemistry in periodic mesoporous hosts, Chem. Mater., 10 (1998) 2950-2963.

[13] J.D. Bass, A. Katz, Bifunctional surface imprinting of silica: Thermolytic synthesis and characterization of discrete thiol-amine functional group pairs, Chem. Mater., 18 (2006) 1611-1620.

[14] J.C. Hicks, C.W. Jones, Controlling the Density of Amine Sites on Silica Surfaces Using Benzyl Spacers, Langmuir, 22 (2006) 2676-2681.

[15] W.-J. Son, J.-S. Choi, W.-S. Ahn, Adsorptive removal of carbon dioxide using polyethyleneimine-loaded mesoporous silica materials, Microporous Mesoporous Mater., 113 (2008) 31-40.

[16] F. Krohm, H. Didzoleit, M. Schulze, C. Dietz, R.W. Stark, C. Hess, B. Stühn, A. Brunsen, Controlling Polymerization Initiator Concentration in Mesoporous Silica Thin Films, Langmuir, 30 (2013) 369-379. 
[17] S.L. Burkett, S.D. Sims, S. Mann, Synthesis of Hybrid Inorganic-Organic Mesoporous Silica by Co-condensation of Siloxane and Organosiloxane Precursors, Chem. Commun., (1996) 1367-1368.

[18] A. Mehdi, C. Reye, R. Corriu, From Molecular Chemistry to Hybrid Nanomaterials. Design and Functionalization, Chem. Soc. Rev., 40 (2011) 563-574.

[19] A.R. Balkenende, F.K. de Theije, J.K. Kriege, Controlling dielectric and optical properties of ordered mesoporous organosilicate films, Adv. Mater., 15 (2003) 139-143.

[20] R. Vathyam, E. Wondimu, S. Das, C. Zhang, S. Hayes, Z. Tao, T. Asefa, Improving the adsorption and release capacity of organicfunctionalized mesoporous materials to drug molecules with temperature and synthetic methods, J. Phys. Chem. C, 115 (2011) 13135-13150.

[21] Q. Zheng, Y. Zhu, J. Xu, Z. Cheng, H. Li, X. Li, Fluoroalcohol and fluorinated-phenol derivatives functionalized mesoporous SBA-15 hybrids: high-performance gas sensing toward nerve agent, J. Mater. Chem., 22 (2012) 2263-2270.

[22] E.J. Acosta, C.S. Carr, E.E. Simanek, D.F. Shantz, Engineering Nanospaces: Iterative Synthesis of Melamine-Based Dendrimers on AmineFunctionalized SBA-15 Leading to Complex Hybrids with Controllable Chemistry and Porosity, Adv. Mater., 16 (2004) 985-989.

[23] J.P. Reynhardt, Y. Yang, A. Sayari, H. Alper, Polyamidoamine Dendrimers Prepared Inside the Channels of Pore-Expanded Periodic Mesoporous Silica, Adv. Funct. Mater., 15 (2005) 1641-1646.

[24] X. Zhao, X.Y. Bao, W. Guo, F.Y. Lee, Immobilizing catalysts on porous materials, Mater. Today, 9 (2006) 32-39.

[25] J.D. Lunn, D.F. Shantz, Peptide Brush-Ordered Mesoporous Silica Nanocomposite Materials, Chem. Mater., 21 (2009) 3638-3648.

[26] C. Sanchez, P. Belleville, M. Popall, L. Nicole, Applications of advanced hybrid organic-inorganic nanomaterials: from laboratory to market, Chem. Soc. Rev., 40 (2011) 696-753.

[27] M. Kruk, Surface-Initiated Controlled Radical Polymerization in Ordered Mesoporous Silicas, Isr. J. Chem., 52 (2012) 246-255.

[28] Q.W. Feng, J.G. Xu, H. Dong, S.X. Li, Y. Wei, Synthesis of polystyrene-silica hybrid mesoporous materials via the nonsurfactant-templated sol-gel process, J. Mater. Chem., 10 (2000) 2490-2494.

[29] Q. Fu, G.V.R. Rao, T.L. Ward, Y.F. Lu, G.P. Lopez, Thermoresponsive transport through ordered mesoporous silica/PNIPAAm copolymer membranes and microspheres, Langmuir, 23 (2007) 170-174.

[30] H. Zou, S.S. Wu, J. Shen, Polymer/silica nanocomposites: Preparation, characterization, properties, and applications, Chem. Rev., 108 (2008) 3893-3957.

[31] M. Ma, S.G. Zheng, H.R. Chen, M.H. Yao, K. Zhang, X.Q. Jia, J. Mou, H.X. Xu, R. Wu, J.L. Shi, A combined "RAFT" and "Graft From" polymerization strategy for surface modification of mesoporous silica nanoparticles: towards enhanced tumor accumulation and cancer therapy efficacy, J. Mater. Chem. B, 2 (2014) 5828-5836.

[32] S. Mishra, A. Rawal, L. Nebhani, Imprinting the location of an in-built RAFT agent and selective grafting of polymer chains inside or outside the pores of mesoporous silica nanoparticles, Microporous and Mesoporous Materials, 294 (2020).

[33] S. Mishra, J.M. Hook, L. Nebhani, Priming the pores of mesoporous silica nanoparticles with an in-built RAFT agent for anchoring a thermally responsive polymer, Microporous and Mesoporous Materials, 277 (2019) 60-69.

[34] L.A. Cao, M. Kruk, Grafting of polymer brushes from nanopore surface via atom transfer radical polymerization with activators regenerated by electron transfer, Polymer Chemistry, 1 (2010) 97-101.

[35] M. Kruk, B. Dufour, E.B. Celer, T. Kowalewski, M. Jaroniec, K. Matyjaszewski, Grafting monodisperse polymer chains from concave surfaces of ordered mesoporous silicas, Macromolecules, 41 (2008) 8584-8591.

[36] Z. Zhou, S. Zhu, D. Zhang, Grafting of thermo-responsive polymer inside mesoporous silica with large pore size using ATRP and investigation of its use in drug release, J. Mater. Chem., 17 (2007) 2428-2433.

[37] P. Pasetto, H. Blas, F. Audouin, C. Boissiere, C. Sanchez, M. Save, B. Charleux, Mechanistic insight into surface-initiated polymerization of methyl methacrylate and styrene via ATRP from ordered mesoporous silica particles, Macromolecules, 42 (2009) 5983-5995.

[38] H. Blas, M. Save, C. Boissière, C. Sanchez, B. Charleux, Surface-initiated nitroxide-mediated polymerization from ordered mesoporous silica, Macromolecules, 44 (2011) 2577-2588.

[39] M. Lenarda, G. Chessa, E. Moretti, S. Polizzi, L. Storaro, A. Talon, Toward the preparation of a nanocomposite material through surface initiated controlled/«living» radical polymerization of styrene inside the channels of MCM-41 silica, J. Mater. Sci., 41 (2006) 6305-6312.

[40] C. Bartholome, E. Beyou, E. Bourgeat-Lami, P. Chaumont, F. Lefebvre, N. Zydowicz, Nitroxide-Mediated Polymerization of Styrene Initiated from the Surface of Silica Nanoparticles. In situ Generation and Grafting of Alkoxyamine Initiators, Macromolecules, 38 (2005) 1099-1106.

[41] S. Choi, J.H. Drese, P.M. Eisenberger, C.W. Jones, Application of amine-tethered solid sorbents for direct CO2 capture from the ambient air, Environ. Sci. Technol., 45 (2011) 2420-2427.

[42] S. Choi, J.H. Drese, C.W. Jones, Adsorbent materials for carbon dioxide capture from large anthropogenic point sources, ChemSusChem, 2 (2009) 796-854.

[43] N. Hiyoshi, K. Yogo, T. Yashima, Adsorption of carbon dioxide on amine modified SBA-15 in the presence of water vapor, Chem. Lett., 33 (2004) 510-511.

[44] T.-L. Chew, A.L. Ahmad, S. Bhatia, Ordered mesoporous silica (OMS) as an adsorbent and membrane for separation of carbon dioxide $\left(\mathrm{CO}_{2}\right)$, Adv. Colloid Interface Sci., 153 (2010) 43-57.

[45] A.M. Varghese, G.N. Karanikolos, $\mathrm{CO} 2$ capture adsorbents functionalized by amine - bearing polymers: A review, Int. J. Greenhouse Gas Control, 96 (2020) 103005.

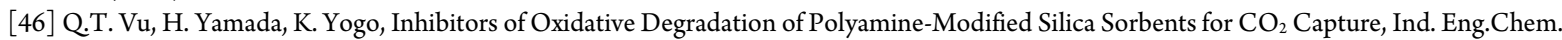
Res., 58 (2019) 15598-15605.

[47] A. Heydari-Gorii, Y. Belmabkhout, A. Sayari, Degradation of amine-supported CO2 adsorbents in the presence of oxygen-containing gases, Microporous Mesoporous Mater., 145 (2011) 146-149.

[48] A. Ahmadalinezhad, A. Sayari, Oxidative degradation of silica-supported polyethylenimine for $\mathrm{CO} 2$ adsorption: insights into the nature of deactivated species, Phys. Chem. Chem. Phys., 16 (2014) 1529-1535.

[49] M.J. Lashaki, S. Khiavi, A. Sayari, Stability of amine-functionalized $\mathrm{CO}_{2}$ adsorbents: a multifaceted puzzle, Chem. Soc. Rev., 48 (2019) $3320-$ 3405 . 
[50] S.A. Didas, R.S. Zhu, N.A. Brunelli, D.S. Sholl, C.W. Jones, Thermal, Oxidative and $\mathrm{CO}_{2}$ Induced Degradation of Primary Amines Used for $\mathrm{CO}_{2}$ Capture: Effect of Alkyl Linker on Stability, J. Phys. Chem. C, 118 (2014) 12302-12311.

[51] A. Heydari-Gorji, A. Sayari, Thermal, Oxidative, and $\mathrm{CO}_{2}$-Induced Degradation of Supported Polyethylenimine Adsorbents, Ind. Eng. Chem. Res., 51 (2012) 6887-6894.

[52] C.S. Srikanth, S.S.C. Chuang, Spectroscopic Investigation into Oxidative Degradation of Silica-Supported Amine Sorbents for $\mathrm{CO}_{2} \mathrm{Capture}$ ChemSuschem, 5 (2012) 1435-1442.

[53] G.J. Zhang, P.Y. Zhao, Y. Xu, Z.X. Yang, H.Z. Cheng, Y.F. Zhang, Structure Property- $\mathrm{CO}_{2}$ Capture Performance Relations of AmineFunctionalized Porous Silica Composite Adsorbents, Acs Appl. Mater. Interfaces, 10 (2018) 34340-34354.

[54] A. Holewinski, M.A. Sakwa-Novak, C.W. Jones, Linking $\mathrm{CO}_{2}$ Sorption Performance to Polymer Morphology in Aminopolymer/Silica Composites through Neutron Scattering, J. Am. Chem. Soc., 137 (2015) 11749-11759.

[55] J. Vinas, N. Chagneux, D. Gigmes, T. Trimaille, A. Favier, D. Bertin, SG1-based alkoxyamine bearing a N-succinimidyl ester: A versatile tool for advanced polymer synthesis, Polymer, 49 (2008) 3639-3647.

[56] B. Schmidt, N. Elizarov, R. Berger, F. Holter, Scope and limitations of the Heck-Matsuda-coupling of phenol diazonium salts and styrenes: a protecting-group economic synthesis of phenolic stilbenes, Org. Biomol. Chem., 11 (2013) 3674-3691.

[57] A.D. Wiersum, C. Gioyannangeli, D. Vincent, E. Bloch, H. Reinsch, N. Stock, J.S. Lee, J.S. Chang, P.L. Llewellyn, Experimental Screening of Porous Materials for High Pressure Gas Adsorption and Evaluation in Gas Separations: Application to MOFs (MIL-100 and CAU-10), Acs Comb. Sci., 15 (2013) 111-119.

[58] E.W. Lemmon, H.M. McLinden, Reference Fluid Thermodynamic and Transport Properties Database (REFPROP), in, National Institute of Standards and Technology, Gaithersburg, 2007.

[59] C.G. Göltner, B. Smarsly, B. Berton, M. Antonietti, On the microporous nature of mesoporous molecular sieves, Chem. Mater., 13 (2001) $1617-1624$.

[60] C. Knöfel, J. Descarpentries, A. Benzaouia, V. Zeleňák, S. Mornet, P. Llewellyn, V. Hornebecq, Functionalised micro-/mesoporous silica for the adsorption of carbon dioxide, Micro Meso Mater, 99 (2007) 79-85.

[61] W. Chaikittisilp, R. Khunsupat, T.T. Chen, C.W. Jones, Poly (allylamine)-Mesoporous silica composite materials for $\mathrm{CO}_{2}$ capture from simulated flue gas or ambient air, Ind. Eng. Chem. Res., 50 (2011) 14203-14210.

[62] L. Wang, L. Ma, A. Wang, Q. Liu, T. Zhang, $\mathrm{CO}_{2}$ adsorption on SBA-15 modified by aminosilane, Chinese J. Catal., 28 (2007) 805-810.

[63] Y.J. Han, J.H. Kang, H.E. Kim, J.H. Moon, C.H. Cho, C.H. Lee, Separation of Carbon Dioxide and Methane Mixture by an Adsorbent/Membrane Hybrid System Using Zeolite 5A Pellets and FAU-Zeolite Membrane, Ind. Eng. Chem. Res., 56 (2017) 2582-2591.

[64] L. Liu, G.J. Zou, B.Q. Yang, X. Luo, S. Xu, Amine-Functionalized Mesoporous Silica @ Reduced Graphene Sandwichlike Structure Composites for $\mathrm{CO}_{2}$ Adsorption, Acs Appl. Nano Mater., 1 (2018) 4695-4702. 
Scheme 1. Synthesis of functional polymers bearing triethoxysilane end group.
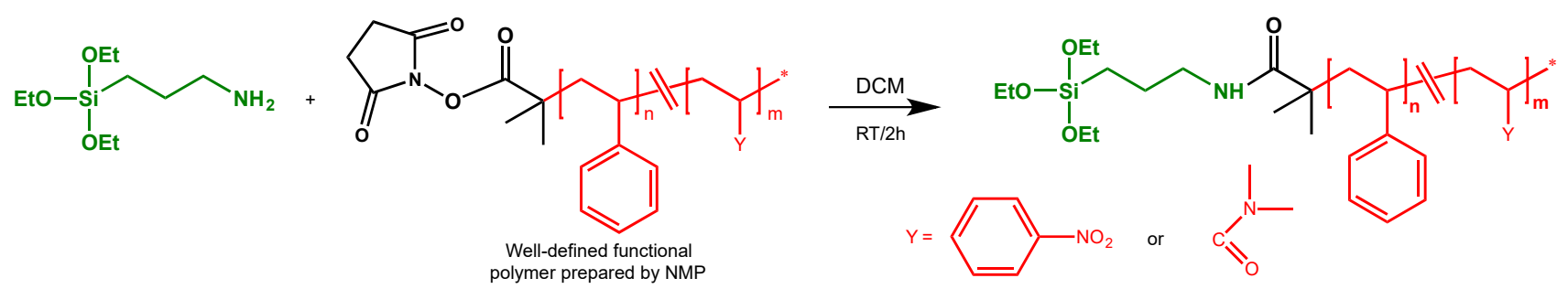


\section{Tables}

Table 1. Experimental data used for the synthesis of polystyrene and styrene-based copolymers.

\begin{tabular}{|c|c|c|c|c|c|c|c|}
\hline Entry & (Co)polymer & $\begin{array}{l}\mathrm{m}_{\text {styrene }} \\
(\mathrm{g})\end{array}$ & $\begin{array}{l}\mathrm{m}_{\text {comonomer }} \\
\text { (g) }\end{array}$ & $\begin{array}{l}\text { mMAMA-NHS }_{\text {M }} \\
(\mathrm{g})\end{array}$ & $\begin{array}{l}{\overline{M_{n}}}^{\mathrm{a}} \\
\left(\mathrm{g} \mathrm{mol}^{-1}\right)\end{array}$ & $\mathrm{D}^{\mathrm{a}}$ & $\begin{array}{l}\text { weight ratio } \\
\text { S/comonomer } \\
(\%)\end{array}$ \\
\hline 1 & PS & 1.51 & l & 0.30 & 2200 & 1.10 & $100 / 0$ \\
\hline 2 & $\mathrm{P}(\mathrm{NS}-\mathrm{co}-\mathrm{S})$ & 1.30 & 0.62 & 0.38 & 2500 & 1.27 & $47 / 53$ \\
\hline 3 & $\mathrm{P}(\mathrm{DMA}-\mathrm{CO}-\mathrm{S})$ & 2.0 & 0.80 & 0.30 & 3200 & 1.52 & $75 / 25$ \\
\hline
\end{tabular}

${ }^{a}$ Determined by size exclusion chromatography. ${ }^{b}$ Determined by ${ }^{1} \mathrm{H}$ NMR analysis.

Table 2. Experimental data of Polymer Functionalized Mesoporous Silicas (MS).

\begin{tabular}{|c|c|c|c|c|c|c|}
\hline Entry & Sample & $\begin{array}{l}\text { SEO } \\
\text { template } \\
\text { a }\end{array}$ & $\begin{array}{l}\text { (co)polymer } \\
\text { mass (mg) }\end{array}$ & Process & $\begin{array}{l}\text { Weight loss } \\
\text { at } 500^{\circ} \mathrm{C} \\
(\%)^{b}\end{array}$ & $\begin{array}{l}\text { S/comonomer } \\
(\mathrm{mmol} / \mathrm{g} \text { silica })^{\mathrm{c}}\end{array}$ \\
\hline 1 & S@MS_C1 & SEO1 & 50 & EISA & 15.61 & $1.50 / 0$ \\
\hline 2 & S@MS_C1-p & SEO1 & 50 & Precipitation & 13.29 & $1.28 / 0$ \\
\hline 3 & S@MS_C2-p & SEO1 & 100 & Precipitation & 19.02 & $1.83 / 0$ \\
\hline 4 & $\mathrm{NO}_{2} @ \mathrm{MS} \_\mathrm{C} 1$ & SEO1 & 50 & EISA & 19.10 & $0.86 / 0.68$ \\
\hline 5 & $\mathrm{NO}_{2} @ \mathrm{MS} \_\mathrm{C} 2$ & SEO1 & 100 & EISA & 29.70 & $1.34 / 1.06$ \\
\hline 6 & $\mathrm{NO}_{2} @ \mathrm{MS} \_\mathrm{C} 1-\mathrm{p}$ & SEO1 & 50 & Precipitation & 12.53 & $0.57 / 0.45$ \\
\hline 7 & $\mathrm{NO}_{2} @ \mathrm{MS} \_\mathrm{C} 2-\mathrm{p}$ & SEO1 & 100 & Precipitation & 16.76 & $0.76 / 0.60$ \\
\hline 8 & $\mathrm{NO}_{2} @ \mathrm{MS} \_\mathrm{C} 1-\mathrm{SEO} 2$ & SEO2 & 50 & EISA & 20.05 & $0.91 / 0.71$ \\
\hline 9 & $\mathrm{NO}_{2} @ \mathrm{MS} \_\mathrm{C} 2-\mathrm{SEO} 2$ & SEO2 & 100 & EISA & 38.87 & $2.08 / 1.38$ \\
\hline 10 & DMA@MS_C2 & SEO1 & 100 & EISA & 34.15 & $1.54 / 0.86$ \\
\hline
\end{tabular}

${ }^{\mathrm{a}} \mathrm{SEO} 1$ and SEO2 are PS-b-PEO block copolymers of molar masse of 8000 and $10000 \mathrm{~g} \mathrm{~mol}^{-1}$ respectively. ${ }^{\mathrm{b}}$ Determinate by TGA. ${ }^{\mathrm{c}}$ The molar content of styrene and comonomer in mesoporous silica calculated using TGA data and copolymer composition. All experiments were carried out using PS- $b$-PEO block copolymers of molar masse of $8000 \mathrm{~g} \mathrm{~mol}^{-1}$ as template excepted those of entries 8 and 9 used PS- $b$-PEO of $10000 \mathrm{~g} \mathrm{~mol}{ }^{-1}$. Experiments of entries 2, 3, 6 and 7 were performed using precipitation method and the sample name is designated with letter $p$. 
Table 3: Characteristics of polymer functionalized MS and their $\mathrm{CO}_{2}$ adsorption performance

\begin{tabular}{|c|c|c|c|c|c|c|}
\hline Entry & Sample & $\begin{array}{l}\mathrm{S}_{\mathrm{BET}} \\
\left(\mathrm{m}^{2} \mathrm{~g}^{-1}\right)\end{array}$ & $\begin{array}{l}\text { Pore Diameter } \\
(\mathrm{nm})\end{array}$ & $\begin{array}{l}\text { Pore vol- } \\
\text { ume } \\
\left(\mathrm{cm}^{3} \mathrm{~g}^{-1}\right)\end{array}$ & $\begin{array}{l}\mathrm{CO}_{2} \text { adsorp- } \\
\text { tion at } 22 \text { bar } \\
\left(\mathrm{mmol}^{-1}\right)\end{array}$ & $\begin{array}{l}\text { Number of } \\
\mathrm{CO}_{2} \text { adsorbed } \\
\text { at } 22 \text { bars per } \\
\text { comonomer } \\
\text { unit }\end{array}$ \\
\hline 1 & S@MS_C1 & 391 & 8.0 & 0.61 & 2.79 & 1 \\
\hline 2 & S@MS_C1-p & 488 & 5.9 & 0.55 & 2.79 & l \\
\hline 3 & S@MS_C2-p & 345 & 5.0 & 0.37 & 2.09 & l \\
\hline 4 & $\mathrm{NO}_{2} @ \mathrm{MS} \_\mathrm{C} 1$ & 174 & 8.0 & 0.25 & 2.79 & 4.1 \\
\hline 5 & $\mathrm{NO}_{2} @ \mathrm{MS} \_\mathrm{C} 2$ & 63 & 6.6 & 1 & 1.31 & 1.2 \\
\hline 6 & $\mathrm{NO}_{2} @ \mathrm{MS} \_\mathrm{C} 1-\mathrm{p}$ & 441 & 4.0 & 0.35 & 3.89 & 8.6 \\
\hline 7 & $\mathrm{NO}_{2} @ \mathrm{MS} \_\mathrm{C} 2-\mathrm{p}$ & 375 & 3.7 & 0.30 & 3.42 & 5.7 \\
\hline 8 & $\mathrm{NO}_{2} @ \mathrm{MS} \_\mathrm{C} 1-\mathrm{SEO} 2$ & 250 & 8.4 & 0.37 & 3.12 & 4.4 \\
\hline 9 & $\mathrm{NO}_{2} @ \mathrm{MS} \_\mathrm{C} 2-\mathrm{SEO} 2$ & 75 & - & l & 1.58 & 1.1 \\
\hline 10 & DMA@MS_C2 & 31 & 6.0 & 0.04 & 1.35 & 1.8 \\
\hline
\end{tabular}




\section{Figure captions}

Figure 1. Schematic representation of the strategy used for the one-pot preparation of mesoporous silica functionalized reactive polymer.

Figure 2. (a) TGA thermograms of different MS functionalized with (blue line) PS, (red and orange lines) $\mathrm{P}(\mathrm{NS}-\mathrm{Co}-\mathrm{S})$ and (green line) $\mathrm{P}(\mathrm{DMA}-\mathrm{CO}-\mathrm{S})$ prepared by EISA process using two concentrations of functional (co)polymer. (b) TGA thermograms of different PS and P(NS-Co-S) functionalized MS synthesized by EISA and precipitation processes.

Figure 3. Solid state (a) ${ }^{13} \mathrm{C}$ and (b) ${ }^{29} \mathrm{Si} \mathrm{CP}$ MAS NMR of $\mathrm{NO}_{2} @ \mathrm{MS}$ C2, a hybrid silica functionalized with $\mathrm{P}(\mathrm{NS}-\mathrm{CO}-\mathrm{S})$.

Figure 4. TEM images of (a) $\mathrm{NO}_{2} @ \mathrm{MS} \_\mathrm{C} 1$, (b) $\mathrm{NO}_{2} @ \mathrm{MS} \_\mathrm{C} 1$-p and (c) DMA@MS_C2 hybrid materials.

Figure 5. Nitrogen adsorption-desorption isotherms at 77K on $\mathrm{NO}_{2} @ \mathrm{MS} \_\mathrm{C} 1$ hybrid silica series.

Figure 6. Adsorption isotherms of different gases $(\bullet) \mathrm{CO}_{2},(\square) \mathrm{N}_{2}$ and $(\mathbf{\Delta}) \mathrm{CH}_{4}$ at $303 \mathrm{~K}$ on hybrid silica $\mathrm{NO}_{2} @ \mathrm{MS} \_\mathrm{C} 1 \_\mathrm{SEO} 2$ functionalized styrene-based copolymer bearing $\mathrm{NO}_{2}$ groups.

Figure 7. $\mathrm{CO}_{2}$ adsorption of $(\bullet) \mathrm{NO}_{2} @ \mathrm{MS}$ and () $\mathrm{S} @ \mathrm{MS}$ series as function of BET specific surface area at $303 \mathrm{~K}$ and at 22 bars. 


\section{Figures}

Figure 1. Schematic representation of the strategy used for the one-pot preparation of mesoporous silica functionalized reactive polymer.

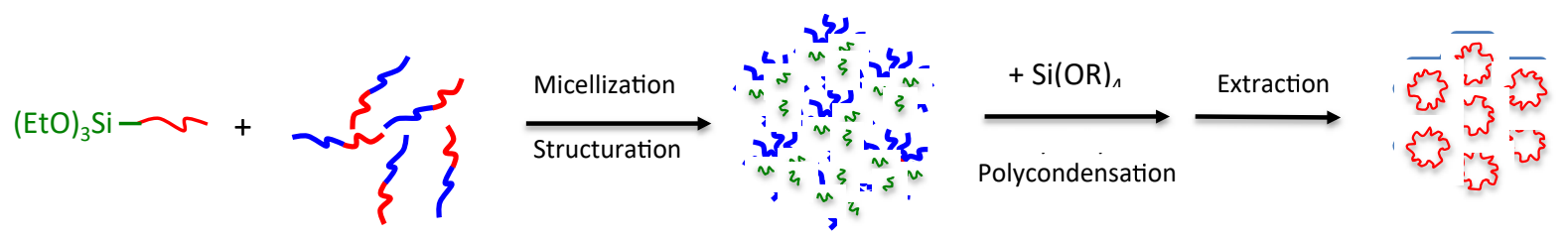

Figure 2. (a) TGA thermograms of different MS functionalized with (blue line) PS, (red and orange lines) $\mathrm{P}(\mathrm{NS}-\mathrm{Co}-\mathrm{S})$ and (green line) $\mathrm{P}(\mathrm{DMA}-\mathrm{CO}-\mathrm{S})$ prepared by EISA process using two concentrations of functional (co)polymer. (b) TGA thermograms of different PS and P(NS-Co-S) functionalized MS synthesized by EISA and precipitation processes.
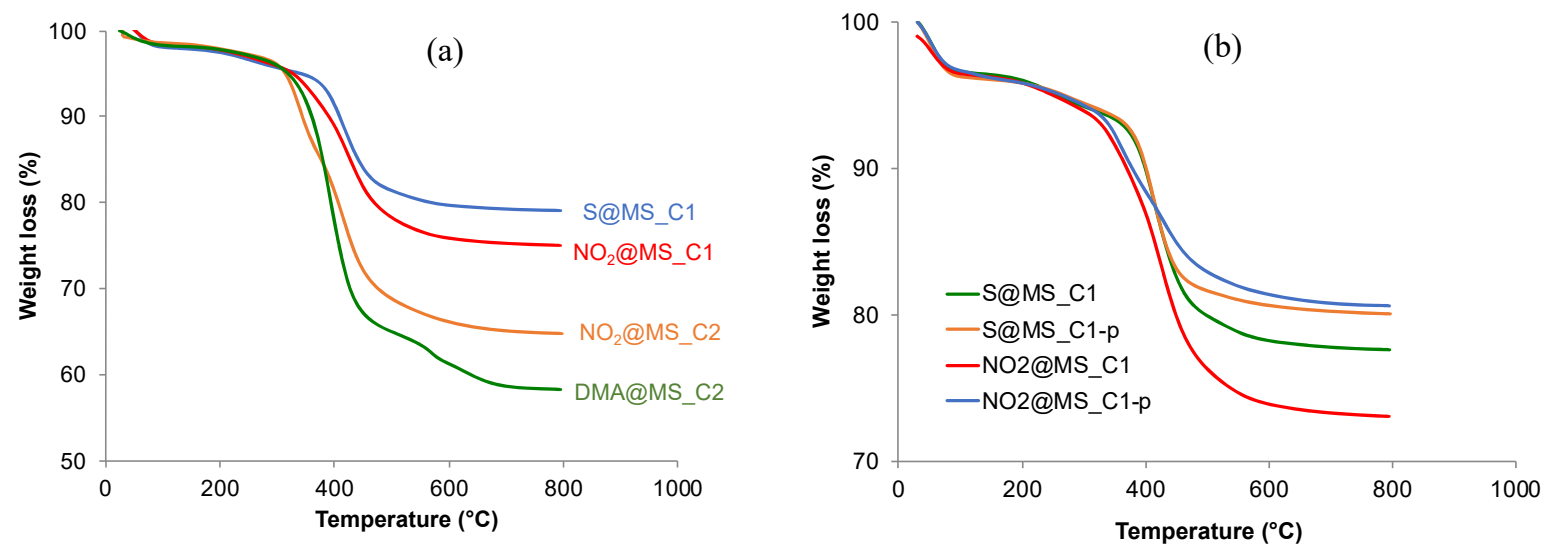
Figure 3. Solid state (a) ${ }^{13} \mathrm{C}$ and (b) ${ }^{29} \mathrm{Si} \mathrm{CP}$ MAS NMR of $\mathrm{NO}_{2} @ \mathrm{MS}$ _C2, a hybrid silica functionalized with $\mathrm{P}(\mathrm{NS}-\mathrm{CO}-\mathrm{S})$.

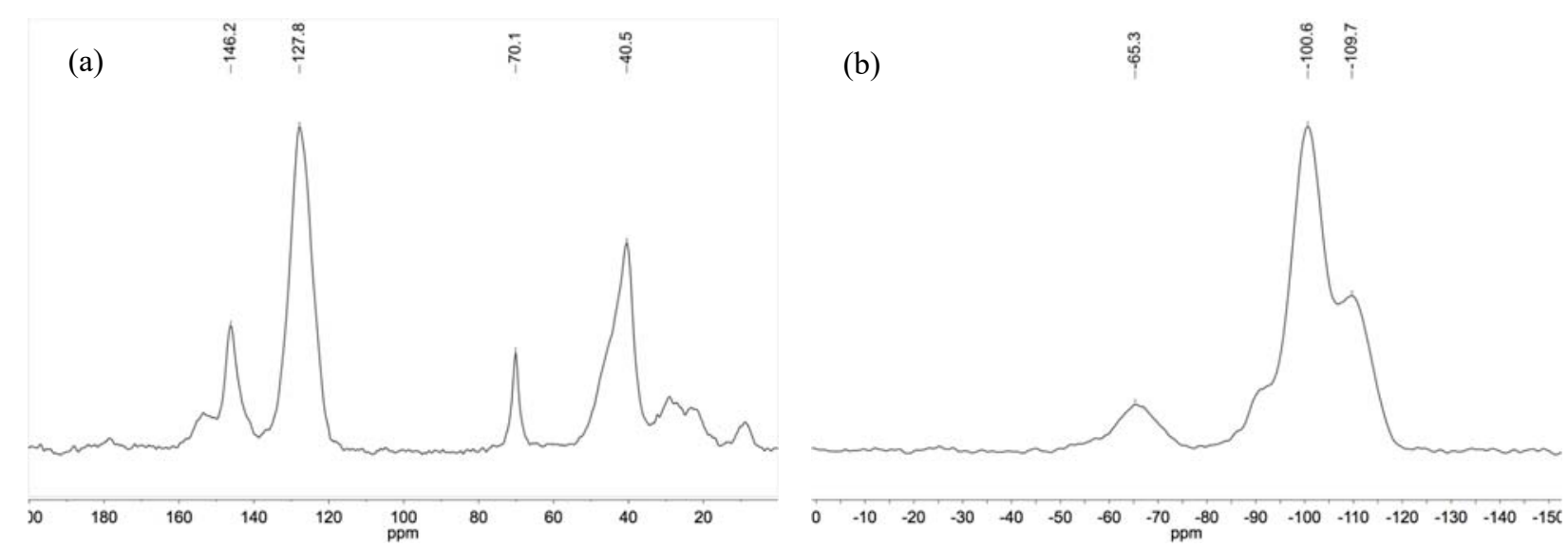

Figure 4. TEM images of (a) $\mathrm{NO}_{2} @ M \mathrm{MS}_{-} \mathrm{C} 1$, (b) $\mathrm{NO}_{2} @ \mathrm{MS} \_\mathrm{C} 1$-p and (c) DMA@MS_C2 hybrid materials.
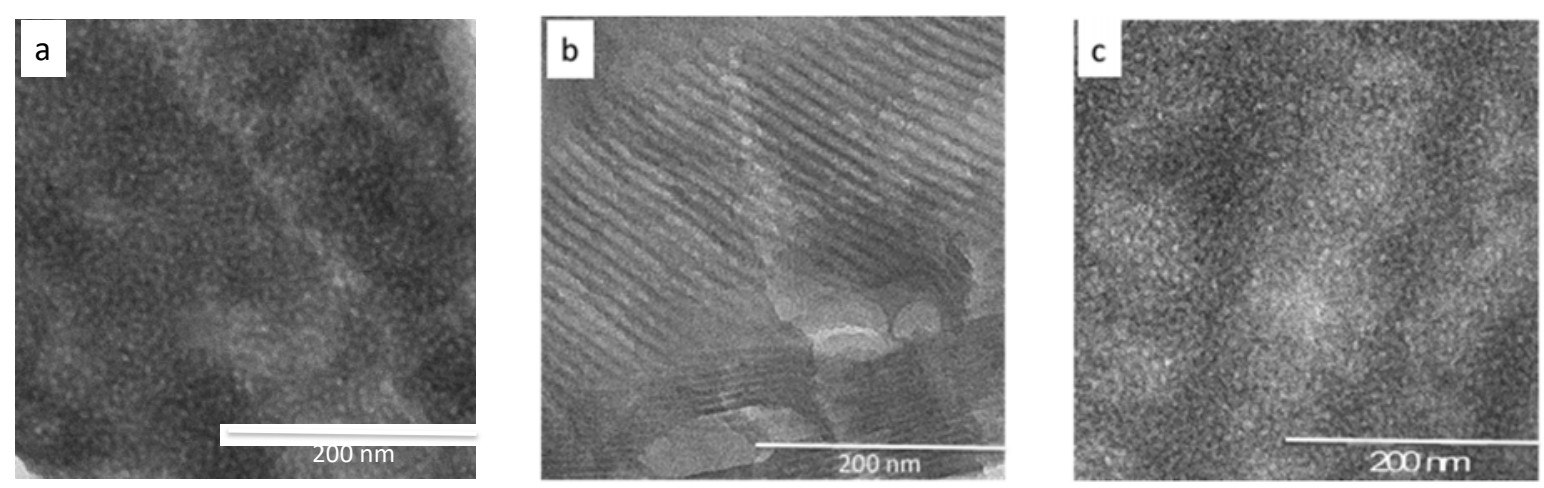
Figure 5. Nitrogen adsorption-desorption isotherms at 77K on $\mathrm{NO}_{2} @ \mathrm{MS} \_\mathrm{C} 1$ hybrid silica series.

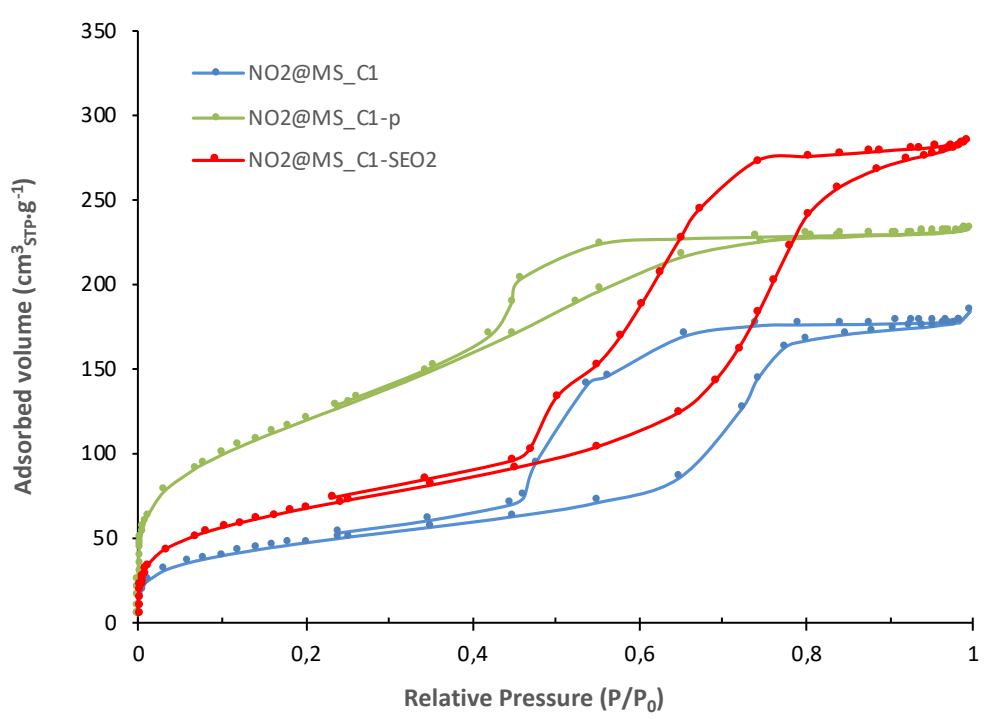

Figure 6. Adsorption isotherms of different gases $(\bullet) \mathrm{CO}_{2},(\square) \mathrm{N}_{2}$ and $(\star) \mathrm{CH}_{4}$ at $303 \mathrm{~K}$ on hybrid silica $\mathrm{NO}_{2} @ \mathrm{MS}$ C1_SEO2 functionalized styrene-based copolymer bearing $\mathrm{NO}_{2}$ groups.

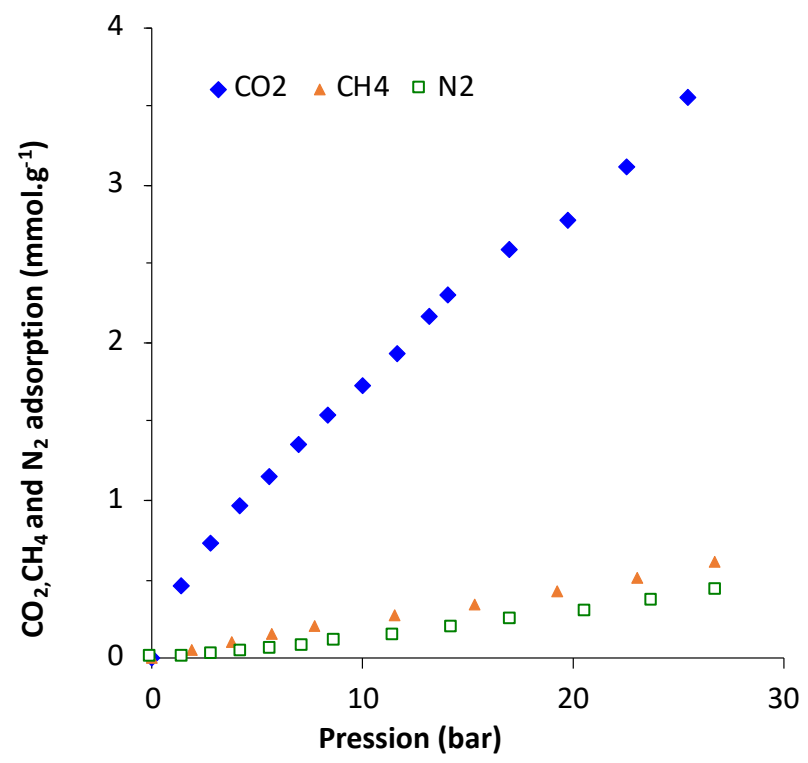


Figure 7. $\mathrm{CO}_{2}$ adsorption of $(\bullet) \mathrm{NO}_{2} @ \mathrm{MS}$ and () $\mathrm{S} @ \mathrm{MS}$ series as function of BET specific surface area at $303 \mathrm{~K}$ and at 22 bars.

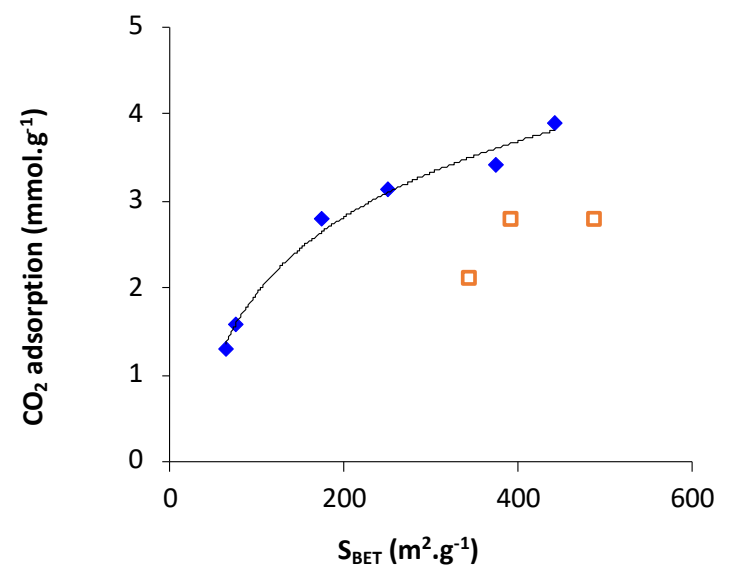




\section{One-Pot Synthesis of Organic Polymer Functionalized Mesoporous Silicas}

Thuy T. T. Ngo, ${ }^{a}$ Eric Besson, ${ }^{\text {a* Emily Bloch, }}{ }^{\mathrm{b}}$ Sandrine Bourrelly, ${ }^{\mathrm{b}}$ Richard Llewellyn, ${ }^{\mathrm{a}}$ Stéphane Gastaldi, ${ }^{a}$ Philip L. Llewellyn, ${ }^{b, c}$ Didier Gigmes, ${ }^{a}$ Trang N. T. Phan ${ }^{a}$ *

${ }^{a}$ Aix Marseille Univ, CNRS, ICR, Marseille, France

${ }^{b}$ Aix Marseille Univ, CNRS, MADIREL, Marseille, France

${ }^{c}$ TOTAL SE, Centre Scientifique et Technique Jean Féger, Pau, France

Figure S1. Micelles size of SEO1 (PEO- $b$-PS) diblock copolymer and its mixture with poly(styrene-co-nitrostyrene) in aquoues medium, data obtained by dynamic light scattering measurements.

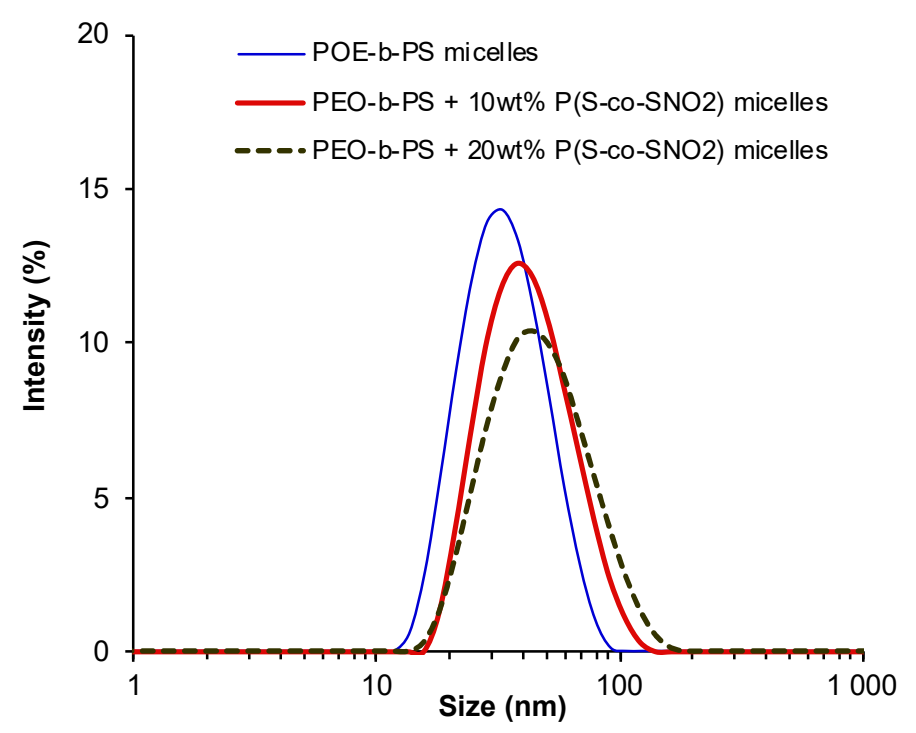


Figure S2. SAXS curves of different hybrid silicas.
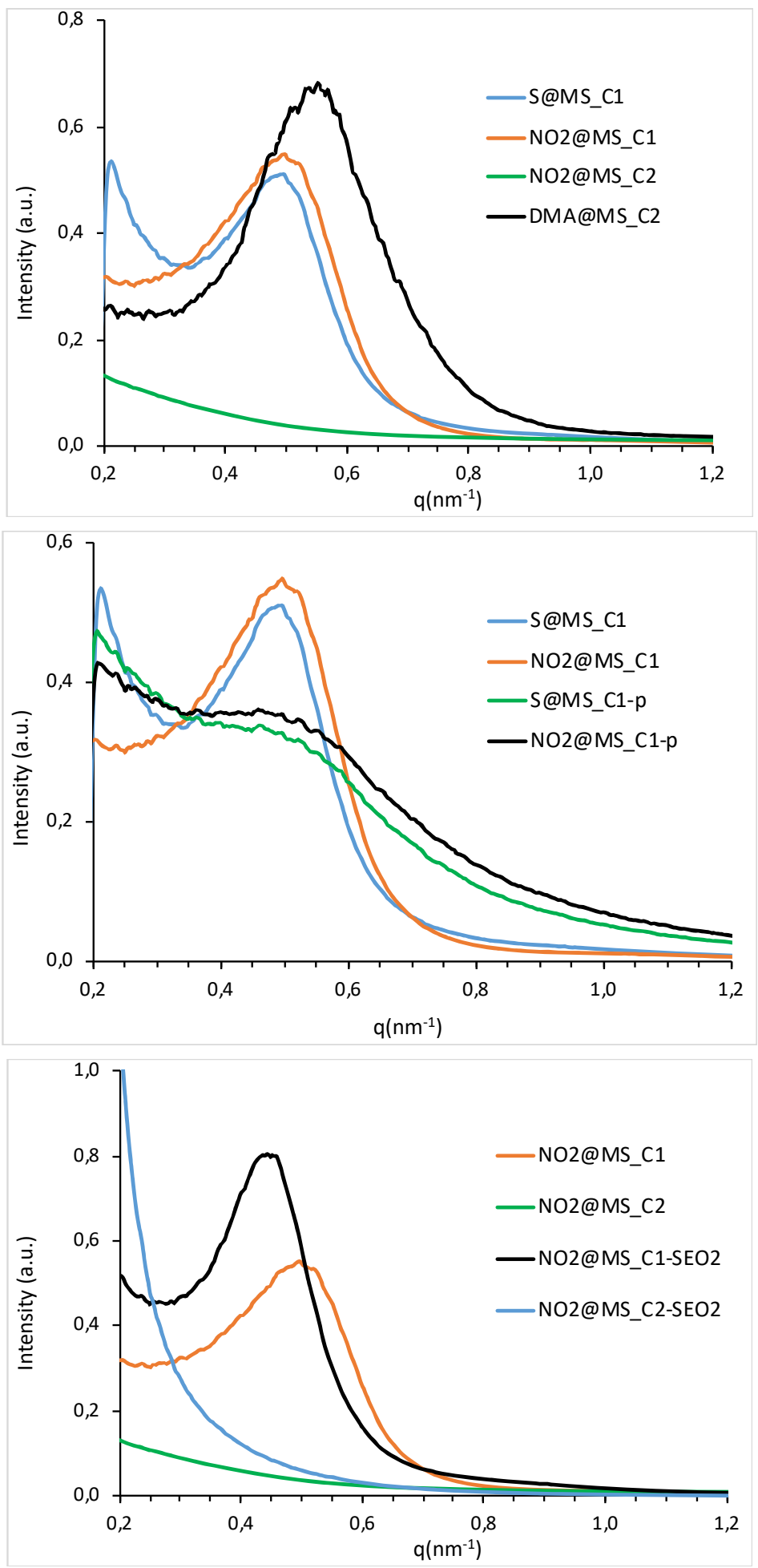